\title{
A Questionnaire Approach Based on the Technology Acceptance Model for Mobile Tracking on Patient Progress Applications
}

\author{
Hussain Mohammad Abu-Dalbouh \\ Department of Computer Sciences, \\ College of Sciences and Arts at Unaizah, Al-Qassim University, Al-Qassim, Saudi Arabia
}

Received 2013-02-21, Revised 2013-04-11; Accepted 2013-06-06

\begin{abstract}
Healthcare professionals spend much of their time wandering between patients and offices, while the supportive technology stays stationary. Therefore, mobile applications has adapted for healthcare industry. In spite of the advancement and variety of available mobile based applications, there is an eminent need to investigate the current position of the acceptance of those mobile health applications that are tailored towards the tracking patients condition, share patients information and access. Consequently, in this study Technology Acceptance Model has designed to investigate the user acceptance of mobile technology application within healthcare industry. The purpose of this study is to design a quantitative approach based on the technology acceptance model questionnaire as its primary research methodology. It utilized a quantitative approach based a Technology Acceptance Model (TAM) to evaluate the system mobile tracking Model. The related constructs for evaluation are: Perceived of Usefulness, Perceived Ease of Use, User Satisfaction and Attribute of Usability. All these constructs are modified to suit the context of the study. Moreover, this study outlines the details of each construct and its relevance toward the research issue. The outcome of the study represents series of approaches that will apply for checking the suitability of a mobile tracking on patient progress application for health care industry and how well it achieves the aims and objectives of the design.
\end{abstract}

Keywords: Mobile Technology, Patient, Methodology, TAM, Tracking

\section{INTRODUCTION}

The implementation of new technology applications to support Healthcare professionals practices requires systematic investments and guiding (McNish, 2001; Meijden et al., 2003; Grimshaw et al., 2004). There is evidence of using a new technology in healthcare industry with exploitation of specific recommendations and guidelines will improve the quality of actions in health care (Wollersheim et al., 2005).

Effective evaluation of healthcare information systems is necessary in order to ensure systems adequately meet the requirements and information processing needs of the users and healthcare organizations. We design a Technology Acceptance Model to investigate user acceptance of mobile technology within the healthcare industry. It proposes a research methodology that being employed to understand the objectives and requirements, design, develop and finally, validate the mobile technology.

Research methodology is defined as procedures, ways, methods and techniques that are employed to capture and gather all the required information for the purpose of the research issue. Methodology refers to that branch of philosophy that analyzes the principles and procedures of an inquiry in a particular discipline. It is generally a guideline for solving a problem that outlines specific components, example: Phases, tasks, methods, techniques, tools and outputs. There are various methods that can be employed in gathering information from different sources such as sampling, site visits and observation of the study environment, questionnaires, 
interviews, prototyping and joint requirement planning. These methods would be applied in order to validate and refine the proposed hypothesis and organized according to structure of study. Thus, the study is organized specially to reflect the proposed research methodology that would be applied to address the proposed research issue. Debates surrounding the field of research reveal two main principal research categories: Quantitative and qualitative. It is important to note that quantitative research has been associated with the positivist stance while qualitative research with the interpretative stance (Creswell, 2011). However, qualitative and quantitative should not be considered synonymous to interpretive and positivist views respectively. In addition, the possibility of qualitative and quantitative research to be either interpretive, positivist, or critical have been proposed. Qualitative research is a type of research that produces findings not arrived at by means of statistical procedures or other means of quantification and the purpose behind the research is the understanding of human experience in order to reveal both the processes by which people construct meaning about their worlds and to report what those meanings are. A qualitative research is considered to be an investigation process that explains social phenomenon through constructing, comparing, replicating, categorizing and classifying the object of the study. In other words, qualitative research is concerned with words rather than numbers (i.e., in data that is not quantifiable). On the other hand, quantitative research is research that relies on developing metrics (numbers) that can be used to describe the phenomena (objects and relationships) under study. It is a deductive process (i.e., logic based on rules, models and laws) consisting of measuring and analyzing the relationship between variables. This process reveals how often or how many people act in a particular way but it fails to answer the question of "why". Table 1 shows the comparison between qualitative and quantitative research.

Table 1. Comparison between qualitative and quantitative rsearch

\begin{tabular}{ll}
\hline Qualitative & Quantitative \\
\hline $\begin{array}{l}\text { What is X } \\
\text { Inductive process } \\
\text { Sample is selective } \\
\text { (non-random) }\end{array}$ & $\begin{array}{l}\text { How many X } \\
\text { Deductive process } \\
\text { Sampling is random } \\
\text { Concepts and hypothesis } \\
\text { ar chosen before the } \\
\text { research begins } \\
\text { Researcher use instrument } \\
\text { to measure the variables } \\
\text { in the study }\end{array}$ \\
$\begin{array}{l}\text { Researcher looks for patterns, } \\
\text { themes and concepts }\end{array}$ & \\
$\begin{array}{l}\text { Researcher develop a theory or } \\
\text { compares patterns with other } \\
\text { theories }\end{array}$ & \\
\hline
\end{tabular}

\section{MATERIALS AND METHODS}

The decision of whether to carry out a qualitative or a quantitative approach lies on the researcher's assumptions (Kanaan, 2009). The present study is based quantitative approach and aquestionnaire is utilized for the purpose of meeting the objectives of the study. We decide on for a quantitative as it helps to provide a description of the trends in a population or a description of the relationships among its variables (Creswell, 2011). In addition to this advantage, a quantitative is also inexpensive to be conducted and it is less time consuming as it enables the researcher to acquire both quantitative scale and qualitative data from a large research sample. For this reason, a questionnaire design coupled with quantitative analysis was employed in the present study to examine the variables in the adoption model and to achieve evaluation of using mobile technology system for tracking patient condition. Moreover, a Likert Scale is applied for each set of questionnaires. The likert scale is designed to examine how strongly subjects agree or disagree with statements on a five-point scale with the following anchors: (1) Strongly disagree, (2) Disagree, (3) Nature, (4) Agree, (5) Strongly agree (Chomeya, 2010). In this study the proposed methodology was developed in five phases. For every phase has process step(s) and output for better understanding of what the main goal of every phase as presented in methodology section.

\subsection{Sampling Technique}

Sampling is a procedure that entails utilizing a small number of units in a given population as a basis for drawing conclusions regarding the whole population (Jemain et al., 2007). The sample is considered as a subset of the population comprising of some members selected from it (Al-Omari et al., 2008). We aim to be able to draw generalized conclusions based on the population under study.

\subsection{Analysis Techniques}

There are three objectives of implementing data analysis: (i) getting overview for the sample data and its attributes, (ii) testing the goodness of data and (iii) validating the proposed hypotheses.

\subsection{Variable Measurement}

The methodology applied in the study is based on the questionnaire approach. The objective of the questionnaire approach is basically to evaluate the 
mobile tracking system. The questionnaire contains: Personal information, perceived usefulness, perceived ease of use, user satisfaction and attribute of usability. All of these have a number of questions constructed to evaluate the effectives of the system mobile tracking model to the intended users.

\subsection{Proposed Methodology}

This methodology is developed based upon a combination of the available literature and the experiences of the author, who are actively involved with the development of using mobile technology in health care industry. Figure 1 shows the phases of a proposed research methodology. The sequence of the phases is not rigid. Moving back and forth between different phases is always required. It depends on the outcome of each phase which phase or which particular output of a phase, has to be performed next. The arrows indicate the most important and frequent dependencies between phases.

\subsection{Phase 1: Problem Background}

This initial phase focuses on understanding the research objectives and requirements from anenvironment perspective, then converting this knowledge into a problem definition and a preliminary plan designed to achieve the objectives. The output of this phase is proposal.

\subsection{Phase 2: Suggestion}

During this phase suggest a tentative design based on the problem definition to achieve the objectives of the study. The output of this phase is tentative design.

\subsection{Phase 3: Development}

The Tentative Design will be implemented. The output of this phase is artifact.

\subsection{Phase 4: Evaluation}

The evaluation was performed to determine the correctness of the system mobile tracking Model. It utilized a quantitative approach based a Technology Acceptance Model (TAM). The output of this phase is acceptance.

\subsection{Phase 4: Result}

The last phase of proposed research methodology, it is the finale of a specific study effort. The output of this phase is documentation.

\subsection{Technology Acceptance Theory}

There are many theoretical perspectives have been developed in order to understand how end users make decisions to use technology applications. Theories provide tools to understand success or failure in implementation processes of new IT applications. The most dominant theories in IT research are Innovation Diffusion Theory (IDT) (Rogers, 1995), Theory of Planned Behavior (TPB) (Fishbein and Ajzen, 1975), the Unified Theory of Acceptance and Use of Technology (UTAUT) (Venkatesh et al., 2003; 2012), the FITT framework (Ammenwerth et al., 2002) and the Technology Acceptance Model (TAM) (Davis 1989; Davis et al., 1989).

Technology Acceptance Model (TAM) (Davis, 1989; Davis et al., 1989) is possibly the most frequently used among all other theories (Ma and Liu, 2004; Kim and Chang, 2007; Yarbrough and Smith, 2007). TAM theory is based on principles adopted from Fishbein and Ajzen (1975) attitude paradigm from psychology, which specifies how to measure the behavior-relevant components of attitudes, distinguishes between beliefs and attitudes and specifies how external stimuli are causally linked to beliefs, attitudes and behavior. The theoretical model on which TAM is based is the Theory of Reasoned Action (TRA). TRA is a general model which is concerned with individuals' intended behaviors. According to TRA an individual's performance is determined by the individual's attitude and subjective norms concerning the behavior in question. In addition an individual's beliefs and motivation interact with existing behavior (Ajzen and Fishbein, 1980).

The Technology Acceptance Model (TAM) determines the user acceptance of any technology perceived usefulness (PU) and perceived ease of use (PEOU) factors. PU defines as the degree to which an individual believes that using a particular system will enhance the task performance. PEOU defines as the degree to which an individual believes that using a particular system is free of physical and mental effort (Davis, 1989; Davis et al., 1989; Davis, 1993). The TAM suggests that intention to accept technology is determined directly by attitude, perceived usefulness and perceived ease of use. According to TAM individuals' intention to use technology determines the actual use of the application and attitudes toward technology affect the intention (Davis et al., 1989; Davis and Venkatesh, 2004; Venkatesh et al., 2012). 


\section{Proposed methodology}



Fig. 1. Proposed methodology

Perceived usefulness and perceived ease factors are affected by various external variables such as level of education (Burton-Jones and Hubona, 2005), gender (Venkatesh and Morris, 2000; Venkatesh et al., 2012), or organizational features such as training in computer use (Venkatesh, 1999; Venkatesh et al., 2012).

TAM theory is widely used in research contexts as well as with several types of technology applications (Chau and Hu, 2001; Lee et al., 2006; Raitoharju, 2007;
Yarbrough and Smith, 2007). TAM uses for generating explanations for the factors of technology acceptance that are transferable to different user populations and different kinds of technologies.

Many different contexts and research constructions have conformed the validity of the TAM model (Ma and Liu, 2004; King and He, 2006), including in health care industry (Chau and Hu, 2002a; 2002b; Chismar and Wiley-Patton, 2003). 
In this study the TAM theory will be used for the purpose of this study, to structure the research process and to help enhance the understanding of the acceptance and use of mobile technology in health care industry. Individual factors such as age, gender and technology skills are external variables in the study. Perceived usefulness is assessed by means of the content and benefits of the mobile tracking on patient progress system and the barriers and facilitators to the implementation of the system. The functionality of the application described perceived ease of use of the system. Attitudes toward mobile technology are taken to consist of motivation to use portable devices, satisfaction with mobile and experience of the benefits of mobile.

\section{RESULTS AND DISCUSSION}

The standard software categorizes quality into functionality, Perceived of Usefulness, Perceived Ease of Use, User Satisfaction and Attribute of Usability. This study aims to design all these categories to investigate the user acceptance of mobile tracking on patient progress in health care industry. From the perspective of TAM, perceived ease of use, perceived usefulness, user satisfaction and attribute of usability are assumed to be related to the acceptance of a computer or technology system, in this study the acceptance of a mobile technology in tracking patient progress system.

High levels of user satisfaction are important to mobile tracking on patient progress system. The effects of four components of satisfaction, Perceived of Usefulness Satisfaction and Satisfaction of Perceived Ease of Use, User Satisfaction and Satisfaction of Attribute of Usability on overall satisfaction among physicians and nurses will investigate. It will discuss about effectiveness of the using mobile technology in healthcare industry.

\subsection{Perceived of Usefulness}

It is defined the degree to which a healthcare professional believes that healthcare industry will be improving by using mobile technology in tracking patient condition. The measurement of perceived usefulness comprises of 5 items modified to the context of this study as shown in Table 2.

\subsection{Perceived Ease of Use}

It refers to the degree to which believes that using the mobile tracking on patient progress system in order to improve the quality of treatment in the hospitals. The measurement of perceived ease of use construct contained 5 items and modified to the context of this study as shown in Table 3.

\subsection{User Satisfaction}

It can be experienced in a variety of situations and connected to system. It is a highly personal assessment that is greatly affected by user expectations. The measurement of user satisfaction construct contained 5 items and modified to the context of this study as shown in Table 4.

\subsection{Attribute of Usability}

It is the area of Human Computer Interaction (HCI) with mobile tracking on patient progress system. It attempts to bridge the gap between human's goals and the system. This is being done by introducing the human issues into the design of interactive mobile tracking on patient progress system and by devising practical techniques to observe human behavior and observe their performance. The measurement of attribute of usability construct contained 5 items and modified to the context of this study as shown in Table 5.

Table 2. Perceived of usefulness items

\begin{tabular}{lll}
\hline Construct & Operational definitions & Measured items \\
\hline Perceived & Perceived usefulness is a & PU1: Mobile tracking on patient \\
of & feeling that doctors and & progress system will enable \\
usefulness & nurses hold & the doctor and nurse \\
& toward the improvement & to get the information of the patient quickly \\
& in tracking patient & PU2: The mobile tracking on patient \\
condition by using & progress system allows the doctor to follow up \\
& mobile tracking technology & the patient condition from outside of the hospital \\
& & PU3: Mobile tracking on patient progress system is useful in the rapid retrieval of \\
& & information from the patient \\
& & PU4: Mobile tracking on patient progress system will save the time of Physicians and nurses \\
& PU5: Using mobile technology would improve my tracking patient condition performance
\end{tabular}


Table 3. Perceived ease of use items

\begin{tabular}{lll}
\hline Construct & Operational definitions & Measured items \\
\hline Perceived & Perceived ease of use refers to & EU1: Learning to operate mobile \\
Ease of Use & tracking on patient progress \\
& and nurses feel when using mobile. & EU2: I would find it easy get mobile tracking on \\
tracking on patient progress system & patient progress system to do what I want it to do \\
& EU3: My interaction with mobile tracking on patient \\
& progress system would be clear and understandable \\
& EU4: I would find mobile tracking on patient progress \\
& system to be flexible to interact with \\
& EU5: It would be easy for me to become skillful at using \\
& mobile tracking on patient progress system \\
\hline
\end{tabular}

Table 4. User satisfaction items

\begin{tabular}{lll}
\hline Construct & Operational definitions & Measured items \\
$\begin{array}{l}\text { User } \\
\text { Satisfaction }\end{array}$ & $\begin{array}{l}\text { User satisfaction refers to a } \\
\text { level of satisfying that } \\
\text { doctors and nurses } \\
\text { of using mobile tracking } \\
\text { on patient progress system }\end{array}$ & $\begin{array}{l}\text { Using the mobile tracking } \\
\text { on patient progress system }\end{array}$ \\
& EU2: I feel very confident in \\
& using the mobile tracking on \\
patient progress system & US3: I found it easy to share information \\
about the patient condition using & mobile tracking on patient progress \\
& US4: I can accomplish the task quickly \\
& using this procedure \\
& US5: I believe that from using mobile \\
& tracking on patient progress system will \\
increase the quality of health care industry
\end{tabular}

Table 5. Attribute of usability items

\begin{tabular}{lll}
\hline Construct & Operational definitions & Measured items \\
\hline Attribute of & Attribute of usability shows up potential issues in the mobile tracking on & AU1: It easy to interact with mobile \\
Usability & patient progress system. The usability helps to get feedback on what & tracking on patient progress \\
& is or isn't working and have a much broader understanding of & AU2: The procedure through mobile \\
& what users. are doing and how they interact with the system system by & tracking on patient \\
& progress using mobile phone system by mobile phone & AU3: I found it easy to decide \\
& visited is clear firstly & which the case need to be \\
& & AU4:I found the various functions \\
& & in this system were well integrate \\
& AU5:I think that I would like to use \\
\end{tabular}

\subsection{Future Work}

Designing A Technology Acceptance Model For Mobile Tracking On Patient Progress Applications is simply a first step in systems development. Looking ahead, for evaluating a mobile tracking solution in monitoring patients after implementation using this questionnaire design.

\section{CONCLUSION}

In fact, increasing and emphasizing on improving the quality of care provided by the hospitals. We created new needs to help and make better choices as using the mobile application on tracking patient's progress. Therefore there is an eminent need to investigate the current position of the acceptance of 
those mobile health applications that are tailored towards the tracking patients' condition, share patients information and access. We proposed methodology designed a Technology Acceptance Model (TAM) approach based on the literature studies aimed to evaluate and investigate usability test for Perceived of Usefulness, Perceived Ease of Use, User Satisfaction and Attribute of Usability as important for the user evaluation in the in Mobile Tracking On Patient Progress System to assess if such this system mobile tracking model will be of much use to the intended users.

\section{ACKNOWLEDGEMENT}

The author wish to thank Al-Qassim university, Saudi Arabia. This study was supported in part by a grant from Deanship of Scientific Research, Al-Qassim University.

\section{REFERENCES}

Ajzen, I. and M. Fishbein, 1980. Understanding Attitudes and Predicting Social Behavior. 1st Edn., Prentice Hall, Englewood Cliffs, ISBN-10: 0139364439, pp: 278.

Al-Omari, A.I., K. Jaber and A. Al-Omari, 2008. Modified ratio-type estimators of the mean using extreme ranked set sampling. J. Math. Stat., 4: 150155. DOI: $10.3844 /$ jmssp.2008.150.155

Ammenwerth, E., F. Ehlers, U. Kutscha, A. Kutscha and R. Eichstadter et al., 2002. Supporting patient care by using innovative information technology. Disease Manage. Health Outcomes, 10: 479-487. DOI: 10.2165/00115677-200210080-00004

Burton-Jones, A. and G.S. Hubona, 2005. Individual differences and usage behavior: Revisiting a technology acceptance model assumption. Database Adv. Inform., 36: 58-77. DOI: 10.1145/1066149.1066155

Chau, P.Y.K. and P.J.H. Hu, 2001. Information technology acceptance by individual professionals: A model comparison approach. Decision Sci., 32: 699-719. DOI: 10.1111/j.1540-5915.2001.tb00978.x

Chau, P.Y.K. and P.J.H. Hu, 2002a. Investigating healthcare professionals' decisions to accept telemedicine technology: An empirical test of competing theories. Inform. Manage., 39: 297-311. DOI: 10.1016/S0378-7206(01)00098-2

Chau, P.Y.K. and P.J.H. Hu, 2002b. Examining a model of information technology acceptance by individual professionals: An exploratory study. J. Manage. Inform. Syst., 18: 297-311.
Chismar, W.G. and S. Wiley-Patton, 2003. Does the extended technology acceptance model apply to physicians. Proceedings of the 36th Annual Hawaii International Conference on System Sciences, Jan. 6-9, IEEE Xplore Press, pp: 160-167. DOI: 10.1109/HICSS.2003.1174354

Chomeya, R., 2010. Quality of psychology test between likert scale 5 and 6 points. J. Soc. Sci., 6: 399-403. DOI: $10.3844 /$ jssp.2010.399.403

Creswell, J.W., 2011. Educational Research: Planning, Conducting and Evaluating Quantitative and Qualitative Research. 4th Edn., Pearson Education, Boston, ISBN-10: 0132613948, pp: 650.

Davis, F.D. and V. Venkatesh, 2004. Toward preprototype user acceptance testing of new information systems: Implications for software project management. IEEE Trans. Eng. Manage., 51: 31-46.

Davis, F.D., 1989. Perceived usefulness, perceived ease of use and user acceptance of information technology. MIS Q., 13: 319-340. DOI: $10.2307 / 249008$

Davis, F.D., 1993. User acceptance of information technology: System characteristics, user perceptions and behavioral impacts. Int. J. Man-Mach. Stud., 38: 475-487. DOI: 10.1006/imms.1993.1022

Davis, F.D., R.P. Bagozzi and P.R. Warshaw, 1989. User acceptance of computer technology: A comparison of two theoretical models. Manage. Sci., 35: 9821003. DOI: $10.1287 / \mathrm{mnsc} .35 .8 .982$

Fishbein, M. and I. Ajzen, 1975. Belief, Attitude, Intention and Behavior: An Introduction to Theory and Research. 1st Edn., Addison-Wesley, Reading, Mass., ISBN-10: 0201020890, pp: 578.

Grimshaw, JM., R.E. Thomas, G. MacLennan, C. Fraser and C.R. Ramsay et al., 2004. Effectiveness and efficiency of guideline dissemination and implementation strategies. Health Technol. Assess. 8: 1-73. PMID: 14960256

Jemain, A.A., A. Al-Omari and K. Ibrahim, 2007. Multistage median ranked set sampling for estimating the population median. J. Math. Stat., 3: 58-64.

Kanaan, R.K., 2009. Making sense of e-government implementation in Jordan: A qualitative investigation. PhD Thesis, Center of Computing and Social Responsibility. De Montfort University, Leicester. 
Kim, D. and H. Chang, 2007. Key functional characteristics in designing and operating health information websites for user satisfaction: An application of the extended technology acceptance model. Int. J. Med. Inform., 76: 790-800. DOI: 10.1016/j.ijmedinf.2006.09.001

King, W.R. and J. He, 2006. A meta-analysis of the technology acceptance model. Inform. Manage., 43: 740-755. DOI: 10.1016/j.im.2006.05.003

Lee, S.M., I. Kim, S. Rhee and S. Trimi, 2006. The role of exogenous factors in technology acceptance: The case of object-oriented technology. Inform. Manage., 43: 469-480. DOI: 10.1016/j.im.2005.11.004

Ma, Q. and L. Liu, 2004. The technology acceptance model: A meta-analysis of empirical findings. J. Organ. User Comput., 16: 59-72.

McNish, M., 2001. Guidelines for managing change: A study of their effects on the implementation of new information technology projects in organisations. J. Change Manage., 2: 201-211. DOI: 10.1080/738552754

Meijden, M.J.V.D., H.J. Tange, J. Troost and A. Hasman, 2003. Determinants of success of inpatient clinical information systems: A literature review. J. Am. Inform. Assoc., 10: 235-243. DOI: 10.1197/jamia.M1094

Raitoharju, R., 2007. Information Technology Acceptance in the Finnish Social and Healthcare Sector B Exploring the Effects of Cultural Factors. 1st Edn., Turku School of Economics, Turku, ISBN10: 9515644208, pp: 149.
Rogers, E.M., 1995. Diffusion of Innovations. 4th Edn., Free Press, New York, ISBN-10: 0028740742, pp: 519.

Venkatesh, V. and J.Y.L. Thong and X. Xu, 2012. Consumer acceptance and use of information technology: Extending the unified theory of acceptance and use of technology. MIS Q., 36: 157-178.

Venkatesh, V. and M.G. Morris, 2000. Why don't men ever stop to ask for directions? Gender, social influence and their role in technology acceptance and usage behavior. MIS Q., 24: 115-139. DOI: 10.2307/3250981

Venkatesh, V. and M.G. Morris, G.B. Davis and F.D. Davis, 2003. User acceptance of information technology: Toward a unified view. MIS Q., 27: 425-478.

Venkatesh, V., 1999. Creation of favorable user perceptions: Exploring the role of intrinsic motivation. MIS Q., 23: 239-260. DOI: $10.2307 / 249753$

Wollersheim, H., J. Burgers and R. Grol, 2005. Clinical guidelines to improve patient care. Netherlands J. Med., 63: 188-192. PMID: 16011009

Yarbrough, A.K. and T.B. Smith, 2007. Technology acceptance among physicians: A new take on TAM. Med. Care Res. Rev., 64: 650-672. DOI: $10.1177 / 1077558707305942$ 